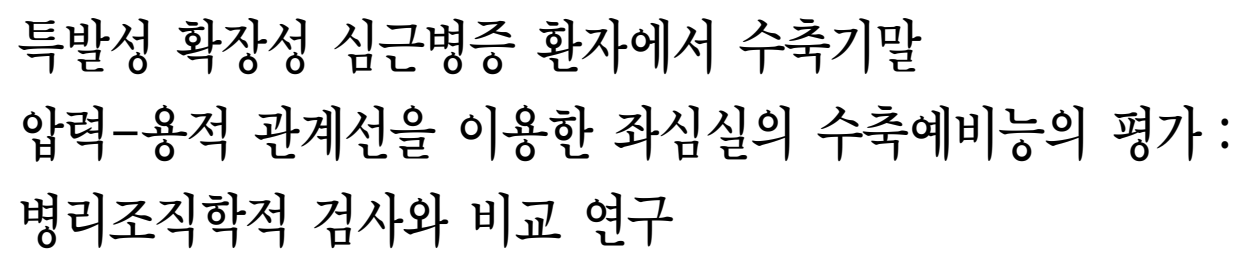

연세대학교 의과대학 심장내과학교실, ${ }^{1}$ 병리학교실, ${ }^{2}$

연세대학교 원주보건과학대학 의용전자공학과학교실 ${ }^{3}$

정남식 ${ }^{1} \cdot$ 장양수 $^{1} \cdot$ 하종원 $^{1} \cdot$ 변영섭 $^{1} \cdot$ 이남호 $^{1}$. 임세중 ${ }^{1}$ - 이문형 ${ }^{1}$

심원흠 ${ }^{1} \cdot$ 조승연 $^{1} \cdot$ 김성순 $^{1} \cdot$ 조상호 $^{2} \cdot$ 윤영로 $^{3} \cdot$ 석주현 $^{3} \cdot$ 신재우 $^{3}$

\title{
Analysis of the Left Ventricular Contractile Reserve Using End-systolic Pressure-Volume Relation (ESPVR) in Idiopathic Dilated Cardiomyopathy : \\ Its Correlation with Pathologic Findings
}

Namsik Chung, MD ${ }^{1}$, Yangsoo Jang, MD ${ }^{1}$, Jong-Won Ha, MD ${ }^{1}$, Young-Seop Byeon, MD ${ }^{1}$, Nam-Ho Lee, MD ${ }^{1}$, Se-Joong Rim, MD ${ }^{1}$, Moon-Hyung Lee, MD ${ }^{1}$, Won-Heum Shim, MD ${ }^{1}$, Seung-Yun Cho, MD ${ }^{1}$, Sung-Soon Kim, MD ${ }^{1}$, Sang-Ho Cho, $\mathrm{MD}^{2}$, Young-Ro Yoon, $\mathrm{PhD}^{3}$, Joo-Hyun Seok ${ }^{3}$ and Jae-Woo Shin $^{3}$

${ }^{1}$ Cardiology Division, Department of ${ }^{2}$ Pathology, Yonsei University College of Medicine, Seoul,

${ }^{3}$ Department of Biomedical Engineering, Yonsei University College of Health Science, Wonjoo, Korea

\section{ABSTRACT}

Background : Left ventricular (LV) end-systolic pressure volume relation (ESPVR) is considered as a load independent contractile index. However, its application in human beings has been limited by the difficulty in the accurate real time measurement of the LV volume changes. With introduction of the echocardiographic automatated edge detection method, on-line generation of multiple LV pressure volume-loops has become possible to assess ESPVR. This study was performed to investigate the correlation of the degree of myocardial damages with myocardial contractility and contractile reserve assessed by ESPVR as a surrogate of contractility index. Methods : Studies were attempted in ten patients with idiopathic dilated cardiomyopathy. Baseline two-dimensional and Doppler echocardiography, cardiac catheterization for hemodynamicassessment and endomyocardial biopsy were performed. Generation of multiple LV pressure-volume loops during occlusion and release of the inferior vena cava by a balloon catheter was performed using the volume signals from the echocardiographic automatated edge detection method and the pressure signals from a $5 \mathrm{~F}$ fluid-filled lumen catheter. ESPVR was measured at the baseline and after 3 minutes of dobutamin infusion ( $10 \mu \mathrm{g} / \mathrm{Kg} / \mathrm{min})$. Results : No correlation was observed between the degree of myocyte hypertrophy change or interstitial fibrosis and the two-dimensional echocardiographic or hemodynamic data. However, restrictive LV filling pattern was more common in the patients with severe degree of myocyte hypertrophy change. Myocardial

교신저자 : 정남식, 120- 752 서울 서대문구 신촌동 연세대학교 의과대학 심장내과학교실

전화 : (02) 363- 7071. 전송 : (02) 393- 2041

E-mail : namsikc@yumc.yonsei.ac.kr 
contractility and contractile reserve were also significantly reduced in this patient group. The degree of interstitial fibrosis did not affect myocardial contractility or contractile reserve in this particular patient group. Conclusion : Assessment of ESPVR using the echocardiographic automatated edge detection method was feasible in the patients with idiopathic dilated cardiomyopathy. The degree of myocardial hypertrophy change was prominent in the patients with reduced contractility and contractile reserve. (Korean Circulation J 1999; 29(7):751-761)

KEY WORDS : LV function · ESPVR · Pressure-volume loop · Dilated cardiomyopathy.

\section{서 론}

특발성 확장성 심근병증은 원인이 불분명한 심근질 환으로서 좌심실 또는 좌우심실의 수축력 저하와 함께 확장을 동반하여 울혈성 심부전증을 일으키는 예후가 불량한 질환이다. 이 질환의 불량한 예후를 측정할 수 있는 임상적인 지표들은 환자의 기능적 분류( NYHA Class), S3분마음, 심전도의 이상, 환자의 연령증가등 이 있으며, ${ }^{11}$ 혈역학적인 지표로서 폐동맥쐐기압의 상승, 심박출량의 감소, 저혈압, 폐동맥압의 상승 등이 알려져 있다. ${ }^{1-3) 1012-14)}$ 그 외에 운동능력의 감소, ${ }^{515)}$ 혈액의 $\mathrm{Na}$ 농도의 저하, ${ }^{16) 17)}$ nerepinephrine치의 상 승 ${ }^{16) 18)}$ 그리고 atrial natriuretic peptide와 renin치의 상승 ${ }^{16)}$ 등이 불량한 예후와 관련이 있는 것으로 보고 되고 있다. 하지만 이러한 여러가지 지표보다도 일반적 으로 중요한 것은 좌심실의 수축기능부전의 정도라고 할 수 있겠다. 좌심실 구혈율이 감소할 때 특히 불량한 예후를 초래하는 것으로 알려져 있으나, ${ }^{19)}$ 그 수치가 $25 \%$ 이하인 환자군 만을 대상으로 관찰하였을 때에는 좌 심실 구혈율이 이들 군에 있어서 생존율을 예측하는 데는 그 상관관계가 매우 미약한 것으로 알려져있다. ${ }^{10133202121)}$ 이는 좌심실 구혈율 자체가 심근의 순수한 수축력 외에 도 환자 심장의 부하상태에 따라 많은 영향을 받는 지 표이기 때문인 사료된다. 따라서 이렇게 좌심실 구혈율 이 저하된 환자들에서 부하상태에 영향을 받지않고 심 근의 수축력을 비교적 정확하게 측정하고 평가할 수 있 다면 이러한 환자의 치료에 있어 전략적인 목표수립과 예후의 평가에 있어 많은 도움을 받을 수 있을 것으로 사료된다.

이 연구의 목적은 좌심실 구혈율이 저하된 특발성 확 장형 심근병증 환자에서 부하 상태에 영향을 받지 않 는 심근수축력의 지표로 알려진 좌심실 압력- 용적 관 계선(end- systolic pressure- volume relation, 이하 ESPVR이라 약칭함) 이 심근의 병리학적인 손상 정도 와 상관관계가 있다는 것을 증명하고 심근수축제인 dobutamin을 여한후 심근수축예비능의 정도와 심근의 손상정도의 관계를 규명하고자한다. 이러한 가설의 이 론적인 근거는 심근의 손상은 직접적으로 심근 수축력 을 생성하는데 있어서 가장 중요한 기본적인 actin과 myosin의 작용을 저하시켜 결국 심근의 수축력을 저 하시키기 때문이다.

\section{내용 및 방법}

\section{대 상}

대상환자는 환자의 연령과 성별의 제한이 없었으며 환자가 검사 방법과 목적을 이해하고 동의한 경우에 연 구대상에 포함하였다. 심장의 리듬은 동성정맥을 유지 하면서 좌심실 구혈율이 $35 \%$ 이하인 좌심실의 수축기 능이 저하된 특발성 확장형 심근병증 환자로서 울혈성 심부전증이 있는 경우 적절한 대증요법 후 편안히 누운 상태에서 검사를 시행받을 정도의 치료가 진행된 후에 연구에 포함시켰다. 특별히 조영제에 대한 알러지가 있 는 경우에는 제외하였으며 관상동맥 조영술을 시행하 여 관상동맥이 정상임을 확인 모두 14 명을 대상으로 연구를 진행하였는데 자료분석이 가능한 환자는 10 명

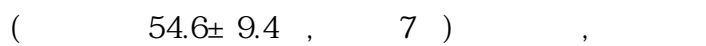
시 NYHA기능분류는 class II 4명, class III 4명, class IV 2 명이었다. 대상환자의 평균 좌심실 구혈율은 $24.6 \pm 7.5 \%$ 이었다.

\section{방 법}

\author{
심초음파 검사 \\ 대상이 되는 환자는 기본적인 이면성 및 Doppler 심
}


초음파 검사를 실시하여 좌심실과 좌심방의 크기를 측 정하고 좌심실의 구혈율은 Quinone등 ${ }^{22)}$ 의 방법을 이 용하였다. 승모판 혈류와 폐정맥 혈류 속도를 PW Doppler 초음파를 이용하여 측정하고 승모판 혈류의 $\mathrm{E}$ wave velocity, E wave의 deceleration time, E/A ratio, A wave의 속도, 수축기와 이완기의 폐정맥 혈류 최대 속도치를 측정하고 좌심방 수축에 의한 역류성 혈 류의 속도를 측정하였다. 좌심실유출로의 직경을 측정 한 다음 이곳에서 PW Doppler을 이용하여 좌심실 유 출로의 혈류속도를 측정하였으며 이의 time velocity integral(LVOT TVI)을 계산하여 심박출량과 심박출 계수를 계산하였다.

\section{심도자 검사와 심근생검}

모든 대상환자는 허혈성 심근병증과 감별을 위하여 관상동맥 조영술을 시행하여 관상동맥이 정상임을 확 인하였다. 혈역학적 검사에서 좌심실의 확장기압, 수축 기압을 측정하고 폐동맥쐐기압 그리고 폐동맥압을 측
정하였다. 상기 검사후 Cordis사 제품의 biotome을 이 용하여 RAO 30도와 LAO 45도에서 우심실쪽의 심실 중격에서 다발적으로 광학 병리조직검사를 위해 세 군 데 이상 심근생검을 시행하였다.

\section{광학 현미경 검사}

이 검사에서는 심근세포의 섬유화 대체를 국소적, 다 발적, 미만적 정도를 관찰하고 심근세포의 구조적인 변 화 여부 정도를 관찰하여 정상 $(0)$, 경증 $(+1)$, 중등증 (+2), 중증 $(+3)$ 으로 분류하였으며 심근세포의 비후정 도도 정상 $(0)$, 경증 $(+1)$, 중등증 $(+2)$, 중증 $(+3)$ 으로 분류하였다(Figs. 1 and 2).

좌심실의 압력 용적 고리(Pressure- Volume Loop) 생성과 $\mathrm{ESPVR}$ 의 측정

Hewlete- Packard사 제품의 Sonos 1500 초음파 장비를 이용하여 apical 4- chamber view에서 실시간 좌심실의 용적(real time LV volume) 을 자동경계탐지

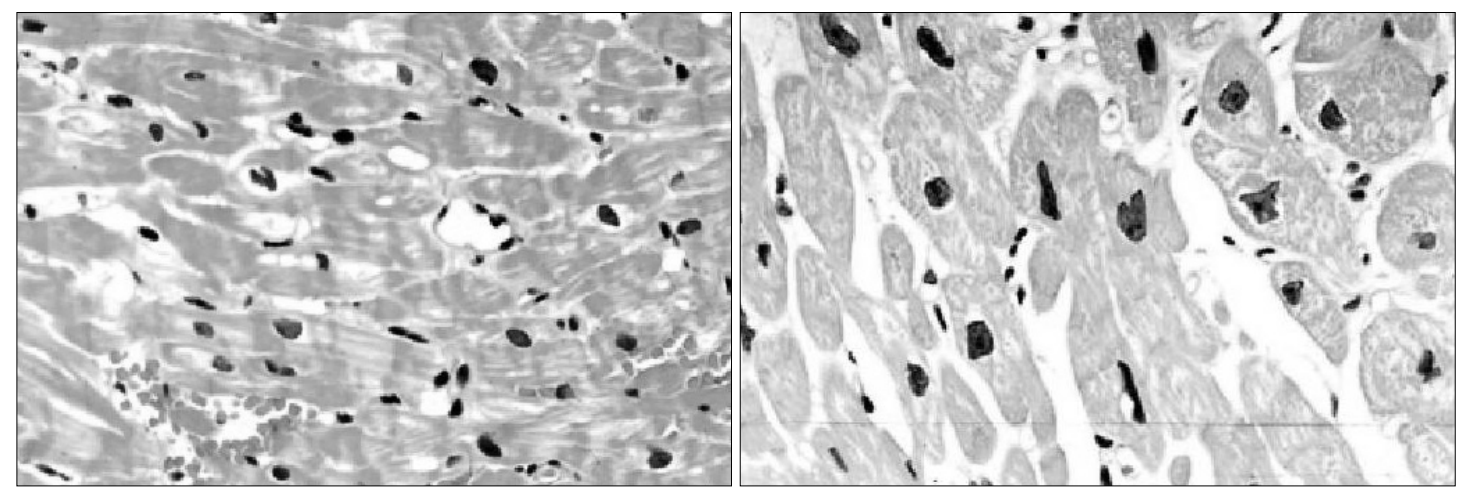

Fig. 1. On the left, mild degree of myocyte hypertrophy change is noted. On the right, severe degree of myocyte hypertrophy change is noted.

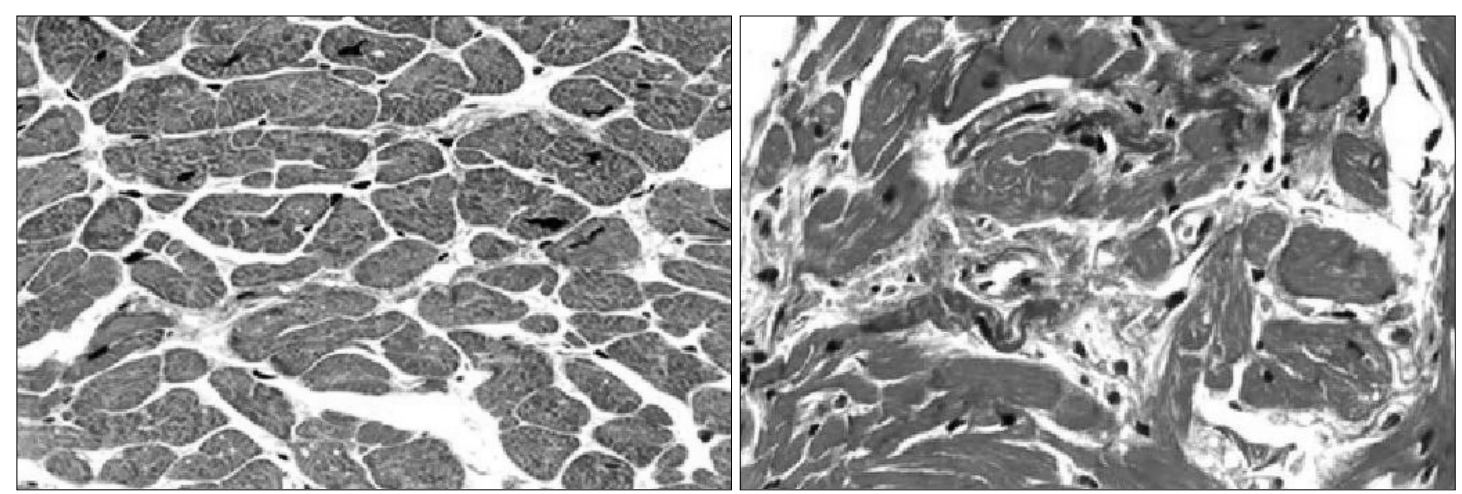

Fig. 2. On the left, mild interstitial fibrosis is noted. On the right, severe degree of interstitial fibrosis is eminent. 


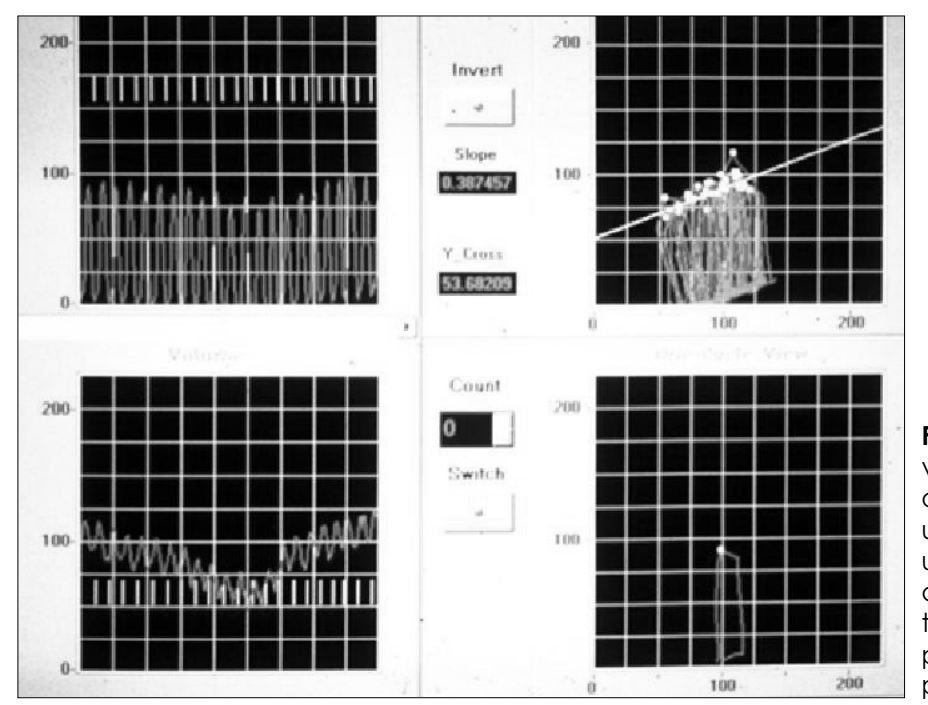

Fig. 3. Generation of multiple pressurevolume loops is depicted with calculation of ESPVR ( the straight line connecting left upper corners of the loops) on the right upper portion. The LV volume curves are depicted on the left lower portion and the LV pressure curves on the left upper portion. On the right lower portion, a single pressure-volume is drawn. 방법(automated edge detection method) 을 이용하 여 측정하고 좌심실의 용적 아날로그 신호( LV volume analog signal)를 20 mses 간격으로 숫자화(digitization) 하였으며 동시에 좌심실 압력은 $5 \mathrm{~F}$ pigtail catheter를 대퇴동맥을 통하여 역으로 좌심실에 삽입 후 실시간으로 측정하면서 이 압력 신호를 좌심실 용적신 호와 마찬가지로 20 mses 간격으로 숫자화( digitization) 하여 같은 실시간의 압력과 용적의 값을 $\mathrm{y}$ 축과 $\mathrm{x}$ 축에 각각 대입하여 압력 용적 고리( pressure- volume loop) 를 생성하였다. 다수의 압력 용적 고리는 하대정맥에 풍선도관( maximum balloon diameter : $3 \mathrm{~cm}$ ) 를 삽입 하여 우심방과 하대정맥 접합부에 위치시키고 풍선을 확장시킨 후 서서히 잡아당겨 하대정맥에서 우심방으 로 들어오는 혈액을 차단함으로서 일시적으로 좌심실 의 전부하를 감소시켜 좌심실의 용적과 압력을 감소를 유도하면서 5 10개 정도의 압력- 용적 고리를 생성하 고 ESPVR을 구하였다(Fig. 3) ${ }^{23)}$ 이렇게 baseline에 서의 ESPVR 값을 구한 다음 dobutamin을 $10 \mu \mathrm{g} / \mathrm{kg} /$ $\min$ 으로 약 3 분간 투여후 꼭 같은 방법으로 ESPVR 값들을 구하여 심근의 수축예비능(contractility reserve) 을 비교 하였다.

\section{자료분석}

환자의 모든 자료는 평균 표준편차로 표시하였으며, 통계는 Mann- Whitney 검증을 이용하였고 $\mathrm{p}$ 값이
0.05 이하인 경우를 의의가 있는 것으로 하였다.

\section{결 과}

모두 14 명의 환자에서 연구를 진행하였으며, 2 명에 서는 심실조기수축이 빈번히 발생하여 분석 가능한 압 력 용적 고리를 얻을 수 없었고 1 예에서는 좋은 심 초음파의 영상을 얻는데 실패하여 분석 가능한 압력용적 고리를 얻을 수 없었다. 또 1예에서는 dobutamin 투여중 심방세동이 발생하면서 좌심실의 용적 변화와 동맥압의 감소 유도에 실패하여 압력- 용적 고리를 얻 을 수 없었다. 따라서 분석이 가능한 대상환자는 모두 10 명이었으며 이들의 임상적인 소견과 혈역학적 검 사소견은 $T$ able 1에 표시하였다. 이면성 심초음파검 사와 Doppler 심초음파검사 소견은 T able 2에 표시 하였으며 병리조직학적 검사소견은 T able 3에 표시 하였다.

이면성 심초음파 검사및 혈역학적 소견과 병리조직학적 검사의 비교

심근의 간질섬유화(interstitial fibrosis) 정도와 심근 세포의 비후성변화(my ocy te hy pertrophy) 를 경증(<2) 군과 중증 $(\geq 2)$ 의 군으로 각각 나누어 비교하였을 때 두 군간의 이면성 심초음파 소견과 혈역학적 소견에는 유의한 차이가 없었다(T able 4 and 5). 
Table 1. Clinical profiles and hemodynamic data

\begin{tabular}{|c|c|c|c|c|c|c|c|c|c|}
\hline Patient & AGE & SEX & BSA & NYHA & MPAP & Aos & AOD & LVEDP & $\mathrm{HR}$ \\
\hline 1 & 63 & $M$ & 1.38 & 2 & 17 & 140 & 80 & 10 & 80 \\
\hline 2 & 57 & $\mathrm{~F}$ & 1.48 & 4 & 9 & 100 & 70 & 10 & 75 \\
\hline 3 & 61 & $M$ & 1.26 & 3 & 26 & 159 & 80 & 20 & 75 \\
\hline 4 & 41 & $\mathrm{~F}$ & 1.86 & 4 & 55 & 120 & 70 & 35 & 75 \\
\hline 5 & 55 & $M$ & 1.26 & 3 & 26 & 159 & 80 & 20 & 75 \\
\hline 6 & 50 & $\mathrm{~F}$ & 1.77 & 3 & 24 & 108 & 53 & 23 & 69 \\
\hline 7 & 64 & $M$ & 1.67 & 2 & 26 & 163 & 81 & 35 & 90 \\
\hline 8 & 51 & $\mathrm{~F}$ & 1.61 & 2 & 22 & 120 & 78 & 15 & 105 \\
\hline 9 & 66 & $\mathrm{~F}$ & 1.67 & 2 & 21 & 120 & 66 & 25 & 74 \\
\hline 10 & 39 & $\mathrm{~F}$ & 1.71 & 3 & 31 & 103 & 59 & 25 & 75 \\
\hline $\begin{array}{l}\text { BSA : bod } \\
\text { NYHA : Ne } \\
\text { MPA : me } \\
\text { HR : }\end{array}$ & $\begin{array}{l}\text { face } \\
\text { ork he } \\
\text { ulmor }\end{array}$ & $\begin{array}{l}\mathrm{m}^{2} \text { ) } \\
\text { socic } \\
\text { irtery }\end{array}$ & $\begin{array}{l}\text { unctio } \\
\text { Jre ( }\end{array}$ & lass & $\begin{array}{l}\text { AOS: } \\
\text { AOD : } \\
\text { LVEDF }\end{array}$ & $\begin{array}{l}\text { lic ac } \\
\text { tolic } \\
\text { end }\end{array}$ & $\begin{array}{l}\text { ressure } \\
\text { pressu } \\
\text { lic pre }\end{array}$ & $\begin{array}{l}\mathrm{mHg}) \\
\mathrm{mmHg}) \\
(\mathrm{mmHg})\end{array}$ & \\
\hline
\end{tabular}

Table 2. Two dimensional and Doppler echocardiography findings

\begin{tabular}{|c|c|c|c|c|c|c|c|c|c|c|c|c|c|c|}
\hline Patient & DT & $E$ & $A$ & $E / A$ & PVS & PVD & PVA & LVEDD & LVESD & LVEDV & LVESV & SV & LV & $E F$ \\
\hline 1 & 80 & 100 & 30 & 3.3 & 24 & 51 & 20 & 72 & 64 & 272 & 209 & 64 & 219 & 21 \\
\hline 2 & 167 & 62 & 90 & 0.7 & 34 & 45 & 27 & 76 & 68 & 307 & 239 & 68 & 262 & 19 \\
\hline 3 & 160 & 85 & 55 & 1.5 & 64 & 49 & 20 & 66 & 55 & 224 & 147 & 76 & 220 & 35 \\
\hline 4 & 113 & 72 & 21 & 3.5 & 53 & 61 & 34 & 69 & 59 & 247 & 173 & 74 & 203 & 27 \\
\hline 5 & 233 & 48 & 36 & 1.3 & 61 & 47 & 18 & 65 & 52 & 216 & 130 & 87 & 283 & 35 \\
\hline 6 & 210 & 59 & 72 & 0.8 & 30 & 31 & 27 & 76 & 66 & 307 & 224 & 84 & 305 & 30 \\
\hline 7 & 110 & 40 & 69 & 0.6 & 28 & 28 & 18 & 72 & 67 & 272 & 231 & 41 & 257 & 18 \\
\hline 8 & 120 & 88 & 19 & 4.7 & 17 & 46 & 31 & 66 & 60 & 224 & 180 & 44 & 272 & 23 \\
\hline 9 & 133 & 89 & 55 & 1.6 & 34 & 58 & 21 & 87 & 74 & 415 & 289 & 126 & 389 & 22 \\
\hline 10 & 127 & 52 & 16 & 3.3 & 25 & 58 & 22 & 66 & 61 & 224 & 187 & 37 & 187 & 14 \\
\hline \multicolumn{7}{|c|}{$\begin{array}{l}\text { DT : deceleration time ( } \mathrm{msec}) \\
\text { E : E velocity }(\mathrm{cm} / \mathrm{sec}) \\
\text { A : A velocity }(\mathrm{cm} / \mathrm{sec}) \\
\text { PVS : systolic pulmonary venous flow }(\mathrm{cm} / \mathrm{sec}) \\
\text { PVD : diastolic pulmonary venous flow }(\mathrm{cm} / \mathrm{sec}) \\
\text { PVA : atrial reversal flow }(\mathrm{cm} / \mathrm{sec})\end{array}$} & & $\begin{array}{l}\text { LVEDD } \\
\text { LVESD : } \\
\text { LVEDV } \\
\text { LVESV: } \\
\text { SV: strc } \\
\text { LV mass }\end{array}$ & $\begin{array}{l}\text { LV enc } \\
\text { LV ensy } \\
\text { : LV enc } \\
\text { LV end } \\
\text { ke volu } \\
\text { : gm }\end{array}$ & $\begin{array}{l}\text { ddiastoli } \\
\text { ystolic d } \\
\text { ddiastoli } \\
\text { dsystolic } \\
\text { ume ( } \mathrm{cm}\end{array}$ & $\begin{array}{l}\text { ic dime } \\
\text { limensio } \\
\text { ic volum } \\
\text { vo volur } \\
n^{3} \text { ) }\end{array}$ & $\begin{array}{l}\text { sion }( \\
(m n \\
(\mathrm{cn} \\
\text { e }(\mathrm{cl}\end{array}$ & & \\
\hline
\end{tabular}

Table 3. Pathological findings of endomyocardial biopsy

\begin{tabular}{ccc}
\hline Patient & MH & IF \\
\hline 1 & +2 & +1 \\
2 & +1 & +2 \\
3 & +3 & +2 \\
4 & +2 & +1 \\
5 & +2 & +1 \\
6 & +1 & +1 \\
7 & +1 & +1 \\
8 & +3 & +3 \\
9 & +2 & +1 \\
10 & +3 & +2 \\
\hline MH : myocyte hypertrophy & IF : interstitial fibrosis
\end{tabular}

Doppler 심초음파 검사 소견과 병리조직학적 검사의 비교

심근의 간질섬유화 (interstitial fibrosis) 정도와 심근 세포의 비후성변화 (my ocyte hy oertrophy) 를 경증 (<2) 과 중증 $(\geq 2)$ 의 군으로 각각 나누어 비교하였을 때 심 근의 비후정도가 심할수록 $\mathrm{E}$ 파의 감속시간이 감소하는 경향을 보였으나 통계학적인 유의성은 없었다. 하지만 의의있게 $\mathrm{E} / \mathrm{A}$ ratio가 증가하고 폐정맥의 Doppler혈류 속도에서 이완기 혈류가 압도하는 소위 제한형 충만형 태(restrictive physiology)의 양상을 보였다. 심근의 간질섬유화 진행정도에서는 경증과 중증의 두 군간에 유의한 Doppler심초음파검사 소견의 차이가 관찰되지 않았다 ( T able 6 and 7). 
Table 4. Findings of two dimensional echocardiography and hemodynamic data according to the degree of myocyte hypertrophy changes

\begin{tabular}{lccc}
\hline & Mild $(<2, \mathrm{~N}=3)$ & Severe $(\geq 2, \mathrm{~N}=7)$ & p-value* \\
\hline 2DE variables & & & \\
LVEDD $(\mathrm{mm})$ & $74.7 \pm 2.31$ & $70.1 \pm 7.82$ & .10 \\
$\operatorname{LVESD}(\mathrm{mm})$ & $67.0 \pm 1.00$ & $60.7 \pm 7.06$ & .09 \\
$\operatorname{LVEDV}\left(\mathrm{cm}^{3}\right)$ & $296 \pm 20.3$ & $260 \pm 71.1$ & .11 \\
LVESV $\left(\mathrm{cm}^{3}\right)$ & $231 \pm 7.82$ & $188 \pm 51.8$ & .09 \\
LV mass $/ \mathrm{BSA}\left(\mathrm{g} / 1.73 \mathrm{~m}^{2}\right)$ & $167 \pm 12.7$ & $159 \pm 41.9$ & .57 \\
Ejection fraction $(\%)$ & $22.3 \pm 6.66$ & $25.6 \pm 8.11$ & .42 \\
Hemodynamic variables & & & .73 \\
Stroke vol $\left(\mathrm{cm}^{3}\right)$ & $52.5 \pm 27.2$ & $53.6 \pm 17.7$ & 1.0 \\
LVEDP $(\mathrm{mmHg})$ & $22.7 \pm 12.5$ & $22.9 \pm 11.1$ & .36 \\
MPAP $(\mathrm{mmHg})$ & $19.8 \pm 9.14$ & $29.4 \pm 13.0$ &
\end{tabular}

Table 5. Findings of two dimensional echocardiography and hemodynamic data according to the degree of interstitial fibrosis

\begin{tabular}{lccc}
\hline & Mild $(<2, \mathrm{~N}=6)$ & Severe $(\geq 2, \mathrm{~N}=4)$ & p-value* \\
\hline 2DE variables & & & \\
LVEDD $(\mathrm{mm})$ & $73.5 \pm 7.56$ & $68.5 \pm 5.00$ & .33 \\
LVESD $(\mathrm{mm})$ & $63.7 \pm 7.50$ & $61.0 \pm 5.35$ & .67 \\
LVEDV $\left(\mathrm{cm}^{3}\right)$ & $288 \pm 69.2$ & $245 \pm 41.8$ & .33 \\
LVESV $\left(\mathrm{cm}^{3}\right)$ & $209 \pm 54.4$ & $188 \pm 38.2$ & .67 \\
LV mass $/ \mathrm{BSA}\left(\mathrm{g} / 1.73 \mathrm{~m}^{2}\right)$ & $164 \pm 39.7$ & $158 \pm 31.8$ & .52 \\
Ejection fraction $(\%)$ & $25.7 \pm 6.65$ & $23.0 \pm 9.42$ & .59 \\
Hemodynamic variables & & & \\
Stroke vol $\left.(\mathrm{cm})^{3}\right)$ & $59.2 \pm 19.2$ & $44.5 \pm 18.2$ & .29 \\
LVEDP $(\mathrm{mmHg})$ & $26.3 \pm 12.2$ & $17.5 \pm 6.46$ & .24 \\
MPAP $(\mathrm{mmHg})$ & $29.5 \pm 14.0$ & $22.0 \pm 9.21$ & .59 \\
\hline
\end{tabular}

*: Mann-whitney tes†

Table 6. Findings of Doppler echocardiography data according to the degree of myocyte hypertrophy change

\begin{tabular}{lcccc}
\hline & Mild & Severe & \\
& $(<2, \mathrm{~N}=3)$ & $(\geq 2, \mathrm{~N}=7)$ & P-value* \\
\hline DT $(\mathrm{msec})$ & $162 . \pm 50.1$ & $138.1 \pm 48.3$ & .57 \\
E $(\mathrm{m} / \mathrm{sec})$ & $53.8 \pm 12.0$ & $76.4 \pm 19.7$ & .14 \\
A $(\mathrm{m} / \mathrm{sec})$ & $76.8 \pm 11.2$ & $33.1 \pm 16.5$ & .02 \\
E/A ratio & $0.70 \pm 0.12$ & $2.76 \pm 1.26$ & .02 \\
PVS $(\mathrm{cm} / \mathrm{sec})$ & $30.8 \pm 2.62$ & $39.8 \pm 19.2$ & .73 \\
PVD $(\mathrm{cm} / \mathrm{sec})$ & $34.6 \pm 9.05$ & $53.0 \pm 6.02$ & .02 \\
PVA $(\mathrm{cm} / \mathrm{sec})$ & $23.9 \pm 4.96$ & $23.7 \pm 6.06$ & .91 \\
PVS TVI $(\mathrm{cm})$ & $7.81 \pm 0.76$ & $9.57 \pm 6.91$ & .73 \\
PVDTVI $(\mathrm{cm})$ & $11.6 \pm 4.71$ & $10.9 \pm 2.60$ & .91 \\
PVATVI $(\mathrm{cm})$ & $2.63 \pm 0.91$ & $3.11 \pm 1.27$ & .49 \\
\hline *: Mann-whitney test & & &
\end{tabular}

ESPVR과 병리조직학적 검사의 비교

심근의 간질섬유화 interstitial fibrosis) 진행정도와 심근세포의 비후성변화 (my ocyte hy oertrophy) 를 경 증 $(<2)$ 과 중증 $(\geq 2)$ 의 군으로 각각 나누어 비교하였을 때 심근세포의 비후성변화가 중증인 군에서 baseline ESPVR값과 dobutamin을 $10 \mu \mathrm{g} / \mathrm{Kg} / \mathrm{min}$ 투여하였을 때 ESPVR값이 모두 감소되어 심근의 수축예비능이 경 증인 군에 비하여 의의있게 감소되었음을 관찰할 수 있 었다. 심근의 간질섬유화가 중증인 군에서는 baseline ESPVR값과 dobutamin을 $10 \mu \mathrm{g} / \mathrm{Kg} / \mathrm{min}$ 투여하였을 때 ESPVR값이 모두 감소하는 경향을 보였으나 통계적 으로는 모두 유의하지 않았다 (T able 8 and 9). 
Table 7. Findings of Doppler echocardiography data according to the degree of interstitial fibrosis

\begin{tabular}{lcccc}
\hline & $\begin{array}{c}\text { Mild } \\
(<2, \mathrm{~N}=6)\end{array}$ & $\begin{array}{c}\text { Severe } \\
(\geq 2, \mathrm{~N}=4)\end{array}$ & P-value* \\
\hline DT $(\mathrm{msec})$ & $146.7 \pm 61.0$ & $143.3 \pm 23.4$ & .67 \\
E $(\mathrm{m} / \mathrm{sec})$ & $68.1 \pm 23.3$ & $72.0 \pm 17.6$ & .83 \\
A $(\mathrm{m} / \mathrm{sec})$ & $47.0 \pm 21.2$ & $44.9 \pm 34.8$ & .67 \\
E/A ratio & $1.86 \pm 1.25$ & $2.56 \pm 1.78$ & .52 \\
PVS $(\mathrm{cm} / \mathrm{sec})$ & $38.5 \pm 14.9$ & $35.0 \pm 20.4$ & .67 \\
PVD $(\mathrm{cm} / \mathrm{sec})$ & $45.9 \pm 13.8$ & $49.7 \pm 5.86$ & 1.0 \\
PVA $(\mathrm{cm} / \mathrm{sec})$ & $22.9 \pm 6.25$ & $25.0 \pm 4.65$ & .29 \\
PVSTVI $(\mathrm{cm})$ & $9.98 \pm 5.63$ & $7.63 \pm 6.39$ & .20 \\
PVSTVI $(\mathrm{cm})$ & $11.4 \pm 2.11$ & $10.6 \pm 4.56$ & .39 \\
PVATVI $(\mathrm{cm})$ & $3.18 \pm 1.37$ & $2.64 \pm 0.16$ & .16 \\
\hline *: Mann-whitney test & & &
\end{tabular}

Table 8. Values of ESPVR according to the degree of myocyte hypertrophy change

\begin{tabular}{lccc}
\hline \multicolumn{1}{c}{ ESPVR$^{* *}$} & $\begin{array}{c}\text { Mild } \\
(<2, \mathrm{~N}=3)\end{array}$ & $\begin{array}{c}\text { Severe } \\
(\geq 2, \mathrm{~N}=7)\end{array}$ & p-value* \\
\hline Baseline & & & \\
Downward slope & $1.79 \pm 0.29$ & $0.91 \pm 0.49$ & .03 \\
Upward slope & $2.57 \pm 0.60$ & $1.42 \pm 0.53$ & .03 \\
Dobutamin $10 \mu \mathrm{g} / \mathrm{kg} / \mathrm{min}$ & & \\
Downward slope & $2.68 \pm 0.67$ & $1.38 \pm 0.85$ & .05 \\
Upward slope & $3.46 \pm 0.60$ & $1.95 \pm 1.04$ & .05 \\
\hline *: Mann-Whitney test, & ${ }^{* *}: \mathrm{mmHg} / \mathrm{ml}$ &
\end{tabular}

Table 9. Values of ESPVR according to the degree of interstitial fibrosis

\begin{tabular}{|c|c|c|c|}
\hline ESPVR** & $\begin{array}{c}\text { Mild } \\
(<2, \mathrm{~N}=6)\end{array}$ & $\begin{array}{c}\text { Severe } \\
(\geq 2, N=4)\end{array}$ & p-value* \\
\hline \multicolumn{4}{|l|}{ Baseline } \\
\hline Downward slope & $1.30 \pm 0.59$ & $0.98 \pm 0.65$ & .45 \\
\hline Upward slope & $1.96 \pm 0.65$ & $1.48 \pm 0.91$ & .29 \\
\hline \multicolumn{4}{|c|}{ Dobutamin $10 \mu \mathrm{g} / \mathrm{kg} / \mathrm{min}$} \\
\hline Downward slope & $2.07 \pm 1.13$ & $1.33 \pm 0.62$ & .29 \\
\hline Upward slope & $2.80 \pm 1.13$ & $1.81 \pm 1.04$ & .29 \\
\hline
\end{tabular}

\section{고 안}

생체 상태에서 환자 심장의 부하상태에 영향을 받지 않고 심근의 수축력을 평가할 수 있는 노력의 일환으로 $\mathrm{Vpm}, \mathrm{V} \max , \mathrm{dp} / \mathrm{dt}_{\max }$ 등의 isovolumic index 를 이용 하고 있으나 이들은 심장의 기능평가에서 2 가지의 중 요 항목인 압력과 용적중 압력만을 표현하는 지표일 뿐 용적에 대한 평가가 결여되어 있으며, 이들 역시 전부
하와 후부하에 의해 영향을 받고 또 수학적 이론에만 근거하고 있으므로 실제 임상적으로 그 응용이 매우 제 한되어 있다. 따라서 부하 상태에 영향을 받지 않는 심 근의 수축력을 반영할 수 있는 지표를 이용하여 심근의 수축력을 측정할 수 있다면 특히 심실수축기능이 저하 된 환자를 정확하게 평가하고 치료의 방침을 결정하거 나 예후를 측정하는데 있어 큰 도움이 될 것이다.

Sagawa는 심장이 시간에 따라서 변화하는 일종의 탄력체라는 개념(time varying elastance model) 하에 전부하나 후부하를 변화시켜 여러 개의 좌심실의 압 력- 용적 고리(pressure- volume loop)를 만든 다음 $\mathrm{E}(\mathrm{t})=\mathrm{P}(\mathrm{t}) N(\mathrm{t})-\mathrm{Vd})($ 여기에서 $\mathrm{E}=$ =elastance, $\mathrm{P}=$ 순간 좌심실 압력, $\mathrm{V}=$ 좌심실 용적, $\mathrm{Vd}=$ positive pressure 를 생성할 수 없는 좌심실의 용적, $\mathrm{t}=$ 시간) 의 방정식 을 이용하여 최대의 maximum elastance $\mathrm{E}(\mathrm{t})$ 값 즉 $\mathrm{Emax}$ 를 구하고 이 값은 각각의 좌심실의 압력- 용적 고리(pressure- volume loop)에서 수축기 말기를 연 결하는 선에 놓이게 되며 이 선은 즉 좌심실 수축기말 압력- 용적관계선(endsystolic pressure- volume relation 이하 ESPVR이라 칭함) ) 은 심근의 수축력을 의 미하고 이 선의 경사도는 오로지 심근 수축력의 변화에 의해서만 영향을 받는다고 하였다. ${ }^{23)}$ 초기에는 Emax 와 ESPVR이 동일한 것으로 인식되었으나 후부하가 심하게 변화할 때는 Emax 값은 ESPVR값보다 횔씬 더 높을 수 있고 항상 Emax와 ESPVR이 일치하지 않음 이 알려졌다. ${ }^{24}{ }^{27)} \mathrm{ESPVR}$ 은 여러 개의 압력 용적고 리(pressure- volume loop)에서 수축기말 점들을 단 순히 연결시킨 선이므로 쉽게 구할 수 있어 E- max대 신 더 널리 심근 수축력의 측정지표로 이용되고 있다. 그 동안 이 지표는 여러 동물실험에서 입증되었지만 ${ }^{28}{ }^{32}$ 인간을 대상으로 한 임상연구에서는 좌심실의 용적을 압력처럼 지속적으로 측정할 수가 없는 애로점과 또 전 부하와 후부하를 변화시키면서 변화하는 좌심실의 용 적 값을 실시간으로 구하기가 어려워 임상적 적용이 어 려웠다. 좌심실의 용적은 conductance catheter를 사 용할 때에 실시간에 측정할 수 있는 장점이 있으나 심 도자 검사실에서 침습적인 방법을 이용해야 하는 단점 이 있고 좌심실의 모형이 변화할 때에는 정확도가 감소 할 수 있다. ${ }^{33)}$ 그 외에 좌심실조영술 또는 radionuclide angiography 등을 이용하여 좌심실의 용적을 측 정해서 좌심실의 수축기말 압력 용적 관계선을 연구한 
논문들이 발표되었다. ${ }^{34}{ }^{44)}$

근래에 integrated backscatter를 이용한 자동경계 탐지방법( automated edge detection method)으로 심 장의 부하상태를 변화시키면서 좌심실의 단면적(cross sectional area) 의 변화와 압력의 변화를 묶어서 다수 의 압력- 단면적 고리(pressure- area loop)를 생성 하고 좌심실의 단면적이 좌심실의 용적변화와 상관관 계가 있는 점을 근거로 수축기말 압력- 단면적 관계선 (end- systolic pressure- area relation)을 이용한 좌심실과 우심실의 수축력 평가에 대한 연구가 발표되 었다. ${ }^{45-49)}$

이러한 자동경계탐지방법( automated edge detection method) 을 더 발전시켜서 이제는 apical 4- chamber view 또는 apical 3- chamber view 에서 Simpson씨 방법과 유사한 방법으로 좌심실의 용적을 측정할 수 있 게 되었으며 좌심실의 용적변화를 실시간으로 그리고 지속적으로 기록할 수 있게 되었다. 따라서 이러한 자 동 경계탐지방법( automated edge detection method) 을 이용하여 ESPVR를 측정할 수 있는 계기가 마련되 었다고 할 수 있겠다. ${ }^{50)}{ }^{51)}$

\section{좌심실의 압력-용적 고리 생성}

본 연구에서는 하대정맥과 우심방의 접합부위에 풍 선도자를 위치 시킨 후 풍선을 부풀리는 방법으로 좌심 방으로 흘러 들어오는 혈류를 막아서 전부하를 감소시 키고 혈압을 강하 시킨 후 다시 풍선의 바람을 빼내어 좌심방으로 들어오는 혈류 유입을 원상대로 복구시키 고 혈압을 정상화시키는 동안에 좌심실의 용적과 압력 의 변화신호를 실시간으로 숫자화 하여 좌심실의 압 력- 용적 고리를 얻었다. 이러한 방법을 시행하는 중에 특별한 부작용은 관찰되지 않았으나 심실 조기수축이 빈번하게 발생하는 경우에는 좌심실의 압력- 용적 고리 를 얻는데 있어 어려운 점이 많아서 수회 반복 시행하 여야 할 경우도 있었다. 간혹 어떠한 경우에서는 급격 한 전부하의 감소로 인한 심장의 위치 변화에 의해 적 절한 좌심실의 초음파 영상을 얻지 못하여 좌심실의 용 적을 얻는데 애로점이 발생하였던 경우도 있었다. 대부 분의 환자에서는 상기와 같은 방법으로 다수의 좌심실 의 압력- 용적 고리를 전부하 감소시킬 때와 원상 복구 시킬 때 얻을 수 있었다.
이면성 심초음파 검사및 혈역학적 소견과 병리조직학적 검사의 비교

본 연구에서는 심근의 비후성변화나 간질섬유화의 진행정도가 이면성 심초음파검사 소견이나 심도자 검 사상의 혈역학적 소견과 연관성을 보이지 않았다. 증례 4의 경우에 좌심실의 확장기말압력이 $35 \mathrm{mmHg}$ 그리 고 폐동맥의 평균 압력이 $55 \mathrm{mmHg}$ 로서 매우 좋지 않 은 혈역학적 소견임에도 심근의 비후성변화는 +2 간 질섬유화는 +1 인 반면, 증례 8 의 경우에는 좌심실의 확장기말압력이 $15 \mathrm{mmHg}$ 그리고 폐동맥의 평균 압력 이 $22 \mathrm{mmHg}$ 로서 매우 양호한 소견이었지만 병리조직 검사상 심근의 비후성변화는 +3 간질섬유화는 +3 으 로서 병리조직학적 검사소견은 매우 양호하지 못하였 다. 이렇게 서로 두 검사간에 연관성이 모자란 요인은 첫째 혈역학적 소견이 환자의 부하상태와 자율신경의 영향에 더 많은 영향을 받기 때문인 점과 둘째 심근의 병리학적인 변화가 미만성으로 발생하지 않고 국소적 으로 발생할 수 있고 심근 생검이 심장의 국소적인 부 위에서만 이루어지기 때문에 심장 전체의 병리조직학 적인 변화를 평가할 때에는 미흡하기 때문이 아닌가 사 료된다.

Doppler 심초음파 검사 소견과 병리조직학적 검사의 비교

심근의 비후성 변화가 심할수록 좌심실의 이완기능 장애가 제한성 충만형태를 보였는데 이는 심근의 조직 학적 변화가 심할수록 좌심실의 이완장애가 더 심하게 진행되어 제한성 충만형태를 보이는 것으로 사료된다. 하지만 간질 섬유화의 진행정도는 좌심실 이완기능장 애의 정도에 별 영항을 미치지 않았는데 이에 대한 해 석은 향후 더 많은 환자를 대상으로 연구를 진행하여 분석함이 바람직할 것으로 사료된다.

\section{ESPVR과 병리조직학적 검사의 비교}

심근세포의 비후성변화가 심한 경우 그렇지 않은 경우 에 비해 좌심실의 구혈율에는 차이가 없더라도 $25.6 \%$ vs 22.3\% $p=0.42$ ) baseline ESPVR치가 유의하게 감소되어 심근의 수축력이 현저하게 감소되어 있음 을 관찰할 수 있었다. 더구나 dobutamin을 투여하여 ESPVR치의 변화를 관찰하였을대에도 심근세포의 비 
후성변화가 심할수록 ESPVR치가 유의하게 감소된 양 상이었으며 baseline에서 dobutamin투여후 ESPVR치 의 증가도 유의하게 작아서 심근의 수축예비능이 감소 되어 있음을 관찰할 수 있었다. 반면에 간질섬유화가 심 하게 진행된 군에서 baseline ESPVR치와 dobutamin 투여시 ESPVR치가 경증인 군에 비해 감소된 양상을 보이면서 diobutamin투여시 baseline에 비해 ESPVR 치의 증가폭이 작아 심근의 수축력과 수축예비능이 감 소된 양상을 나타내었으나 통계학적으로 유의하지는 않 았다. 간질섬유화가 심할수록 심근의 수축력이 당연히 감소할 것으로 생각되는데 본 연구에서는 통계적으로 유의한 수축력과 수축예비능의 감소가 확인되지 않은 점은 향후 더 많은 환자에서 연구를 진행하여 분석함이 필요할 것으로 사료된다.

\section{본 연구의 제한점}

본 연구는 우선 대상환자가 적기때문에 향후 더 많은 환자를 대상으로 간질섬유화의 진행정도와 ESPVR과 의 연관성을 더 정확히 규명하여야 할 것으로 사료된다. 심방세동의 발생이나 존재는 좌심실의 압력- 용적 고리 를 얻는데 있어서 매우 중요한 제한 점이었으며, 검사 중 심방 또는 심실성 부정맥의 발생 역시 적절한 좌심 실의 압력- 용적 고리를 얻는데 있어 방해 요인으로 작 용하였다. 심초음파검사를 이용하여 비침습적으로 좌심 실의 용적을 실시간으로 측정할 수 있으나 심초음파창 (echocardiographic window)이 양호하지 못한 경우 에는 좌심실의 용적을 정확히 측정할 수 없는 단점이 있고 또 좌심실의 압력을 측정하기 위해서는 심도자검 사실에서 침습적인 방법을 이용하여야 하는 단점이 있다.

\section{결 론}

본 연구에서는 특발성 확장성 심근병증 환자에서 심 초음파의 자동경계탐지 방법을 이용하여 좌심실의 실 시간 용적을 측정하고 하대정맥의 혈류를 급격히 차단 하였다가 풀어주는 방법으로 전부하를 변화시키면서 숫 자화된 좌심실의 압력과 용적의 신호를 특수히 제작된 컴퓨터 프로그램을 이용하여 다수의 좌심실 압력- 용적 고리를 만든 다음 심장의 부하상태에 영향을 받지않는 심근 수축력의 평가지표인 ESPVR치를 측정하였다. ESPVR치는 10명의 환자에서 dobutamin투여전(ba seline) 과 dobutamin을 $10 \mu \mathrm{g} / \mathrm{Kg} / \mathrm{min}$ 투여 후 각각 측정하였다. 모든 환자에서 심근 생검을 실시하였으며 이들의 병리조직학적 검사와 이면성 및 Doppler심초음 파 검사소견, 혈역학적 검사소견 그리고 ESPVR치를 비교분석 하였다. 심근의 비후변화가 심한 환자군에서 경한 환자군에 비해 혈역학적 검사소견과 이면성 심초 음파 소견 그리고 좌심실 구혈율에서는 유의한 차이가 없었으나 좌심실 이완기능에서 제한형 충만형태(restrictive filling pattern)를 보이면서 심근의 수축력과 수 축예비능이 유의하게 감소되어 있음을 관찰할 수 있었 다. 간질섬유화가 심하게 발생된 환자군에서는 경하게 진행된 환자군에 비해 혈역학적 검사소견과 이면성 심 초음파 소견 그리고 좌심실 구혈율에서 유의한 차이가 없었고, 심근의 수축력과 수축예비능이 감소하는 경향 을 보였으나 통계학적으로 유의하지는 않았다.

\section{요 약}

\section{연구배경 :}

좌심실의 수축기말 압력- 용적 관계선(end- systolic pressure- volume relation, ESPVR) 은 심장의 부하 에 영향을 받지안는 심근의 수축력 측정 지표로 알려져 있다. 하지만 이의 장점에도 인간에 있어서 이의 응용 은 변화하는 좌심실의 용적을 정확하게 측정할 수 있는 방법의 어려움으로 인하여 매우 제한적으로 이루어져 왔다. 심초음파를 이용한 자동경계탐지방법은 실시간으 로 좌심실의 용적을 비교적 용이하게 측정가능 하게 함 으로서 실시간의 좌심실 압력- 용적 고리를 얻을 수 있 어 ESPVR를 평가할 수 있게 되었다. 본 연구의 목적 은 특발성 확장형 심근병증 환자에서 심근 병리조직학 적 손상이 심근수축력 및 심근수축예비능의 감소와 상 관 관계가 있음을 증명하고자 하였다.

방 법 :

모두 10 명의 특발성 확장형 심근병증 환자를 대상으 로 하였다. 모든 환자에서 기본적인 이면성 및 Doppler 심초음파검사, 혈역학적 자료를 평가하기 위한 심도자 검사 그리고 심근 생검을 시행하였다. 하대정맥과 우심 방의 접합부위에 풍선도자를 위치시킨 후 부풀리는 방 법으로 전부하를 급격하게 변화시키면서 심초음파를 이용한 자동경계탐지방법으로 얻은 좌심실의 용적 신 호와 $5 \mathrm{~F}$ 도자로 측정하는 압력 신호를 숫자화 하여 여 
러 개의 좌심실 압력 용적 고리를 얻었다. ESPVR은 dobutamin투여전(baseline) 과 dobutamin을 3분 이상 (10 $\mu \mathrm{g} / \mathrm{Kg} / \mathrm{min})$ 투여 후 측정하였다.

결 론 :

심근의 비후변화가 심한 환자군에서 경한 환자군에 비해 혈역학적 검사소견과 이면성 심초음파 소견 그리 고 좌심실 구혈율에서는 유의한 차이가 없었으나 좌심 실 이완기능에서 제한형 충만형태(restrictive filling pattern)를 보이면서 심근의 수축력과 수축예비능이 유의하게 감소되어 있음을 관찰할 수 있었다. 간질섬유 화가 심하게 발생된 환자군에서는 경하게 진행된 환자 군에 비해 혈역학적 검사소견과 이면성 심초음파 소견 그리고 좌심실 구혈율에서 유의한 차이가 없었고, 심근 의 수축력과 수축예비능이 감소하는 경향을 보였으나 통계학적으로 유의하지는 않았다.

중심 단어 : 좌심실기능- 좌심실 수축기말 압력- 용적 관계선. 압력- 용적고리 확장형 심근병증.

감사문

본 논문을 진행할 수 있도록 선정하여주신 대한순한기학회와 학술연구비를 기증하여주신 한국 MSD주식회사에 감사드립니 다. 본 논문의 통계적 자문에 응하여 주신 연세의대 의학 통계 학 교실의 남정모 선생님과 논문 작성에 수고하여 주신 김정 훈, 김해진, 송부련 님께도 감사드립니다.

\section{REFERENCES}

1) Sugrue DD, Rodeheffer RJ, Codd MB, Ballard DJ, Fuster V, Gersh BJ. The clinical course of idiopathic dilated cardiomyopathy: A population-based study. Ann Intern Med 1992;117:117-23.

2) Fuster V, Gersh BJ, Giuliani ER, Tajik AJ, Brandenburg $\mathrm{RO}$, Frye RL. The natural history of idiopathic dilated cardiomyopathy. Am J Cardiol 1981;47:525-31.

3) Ikram $\mathrm{H}$, Willianson $\mathrm{Hg}$, Won M, Crozier IG, Wells EJ. The course of idiopathic dilated cardiomyopathy in New Zealand. Br Heart J 1987:57:521-7.

4) Doi YL, Chikamori T, Takata J, et al. Prognostic value of thallium-201 perfusion defects in idiopathic dilated cardiomyopathy. Am J Cardiol 1991;67:188-93.

5) Likoff MJ, Chandler SL, Kay HR. Clinical determinants of mortality in chronic congestive heart failure secondary to idiopathic dilated or ischemic cardiomyopathy. Am J Cardiol 1987;59:643-8.

6) Unverferth DV, Magorien RD, Moeschberger ML, Baker $\mathrm{PB}$, Fetters JK, Leier CV. Factors influencing the oneyear mortality of dilated cardiomyopathy. Am J Cardiol 1984:54:147-52.

7) Schoeller R, Andersen D, Buttner D, Zezcelik R, Vey G, Schroder R. Firstor second-degree atrioventricular block as a risk factor in idiopathic dilated cardiomyopathy. Am
J Cardiol 1993;71:720-6

8) Gradman A, Deedwania P, Cody R, et al. Predictors of total mortality and sudden death in mild to moderate heart failure. J Am Coll Cardiol 1989;14:564-70.

9) Kelly TL, Gremo R, Nielsen C, Shabetai R. Prediction of outcome in late-stage cardiomyopathy. Am Heart $J$ 1990;119:1111-21.

10) Franciosa JA, Wilen M, Ziesche S, Cohn JN. Survival in men with severe chromic left Ventricular failure due to either coronary heart disease of idiopathic dilated cardiomyopathy. Am J Cardiol 1983;51:831-6.

11) Lewis JF, Webber JD, Sutton LL, Chesoni S, Curry CL. Discordance in degree of right and left ventricular dilation in patients with dilated cardiomyopathy: Recognition and clinical implications. J Am Coll Cardiol 1993;21:649-54.

12) Diaz RA, Obasohan A, Oakley CM. Prediction of outcome in dilated cardiomyopathy. Br Heart J 1987;58:393-9.

13) Kuhn H, Becker R, Fischer J, et al. Untersuchungen zur Atiologie, zum Vferlaufund zur Prognose der dilatativen Kardiomyopathio (DCM). Z Kardiol 1982;71:497-508.

14) Komajda M, Jais JP, Reeves F, et al. Factors predicting mortality in idiopathic dilated cardiomyopathy. Eur Heart J 1990;11:824-31.

15) Mancini DM, Eisen H, Kussmaul W, Mull R, Edmunds LH Jr, Wilson JR. Value of peak exercise oxygen consumption for optimal timing of cardiac transplantation in ambulatory patients with heart failure. Circulation 1991; 83:778-86

16) Keogh AM, Baron DW, Hickie JB. Prognostic guides in patients with idiopathic or ischemic dilated cardiomyopathy assessed for cardiac transplantation. Am J Cardiol 1990; $65: 903-8$.

17) Lee WH, Packer M. Prognostic importance of serum sodium concentration and its modification by convertingenzyme inhibition in patients with severe chronic heart failure. Circulation 1986;73:257-67.

18) Rector TS, Olivari MT, Levine TB, Fracis GS, Cohn JN. Predicting survival for an individual with congestive heart failure using the plasma norepinephrine concentration. Am Heart J 1987;114:148-52.

19) Dec GW, Fuster VF. Idiopathic dilated cardiomyopathy. New E J Med 1994;331:1564.

20) Griffin BP, Shah PK, Ferguson J, Ruvbin SA. Incremental prognostic value of exercise hemodynamic variables in chronic congestive heart failure secondary to coronary artery disease or to dilated cardiomyopathy. Am J Cardiol 1991;67:848-53.

21) Saxon LA, Stevenson WG, Middlekauff HR, et al. Predicting death from progressive heart failure secondary to ischemic or idiopathic dilated cardiomyopathy. Am J Cardiol 1993;72:62-5.

22) Quinones MA, Waggoner AD, Reduto LA, Nrlson JG, et al. A new simplified and accurate method for determining ejection fraction with two-dimensional echocardiography. Circulation 1981;64:744-53.

23) Sagawa $\mathrm{K}$. The ventricular pressure-volume diagram revisited. Circ Res 1978;43:677-87.

24) Maughan WL, Sunagawa K, Hunter WC, Sagawa K. Instantaneous but not end-systolic pressure-volume relationship (ESPVR) depends on afterload. Fed Proc 1985; 44:1017(A). 
25) Hunter WC, Janiki JS, Weber KT, Noordergraaf A. Systolic mechanical properties of the LV: Effects of volume and contractile state. Circ Res 1983;52:319.

26) Little WC, Freeman GL. Description of $L V$ pressure-volume relations by time-varying elastance and source resistance. Am J Physiol 1987;253( Heart Cir Physiol 22) :H83.

27) Maughan WL, Kass DA, Heard M, Sagawa K. Erroneous estimation of the end-systolic pressure-volume relationship from time-varying elastance in patients. Circulation 1987; $76($ suppl IV) :IV-545.

28) Suga H, Sagawa K, Shoukas AA. Load independence of the instantaneous pressure-volume ratio of the canine left ventricle and effects of epinephrine and heart rate on the ratio. Circ Res 1973;32:314-22.

29) Little WC, Freeman GL, O'Rourke RA. Simultaneous determination of left ventricular end-systolic pressurevolume and pressure-dimension relationships in closedchest dogs. Circulation 1985;6:1301-8.

30) Kass DA, Yamazaki T, Burkhoff D, Maughan WI, Sagawa K. Determination of left ventricular end-systolic pressurevolume relationships by the conductance (volume) catheter technique. Circulation 1986;3:586-95.

31) Little WC, Cheng C, Peterson T, Vinten-Johansen J. Response of the left ventricular end-systolic pressurevolume relation in conscious dogs to a wide range of contractile states. Circulation 1988;78:736-45.

32) Kass DA, Midei M, Graves W, Brinker JA, Maughan WL. Use of a conductance (volume) catheter and transient inferior vena caval occlusion for rapid determination of pressure-volume relationships in man. Catheterization and Cardiovascular Diagnosis 1988;15:192-202.

33) Chung N, Small RS, Kass DA, Bell MA, Ritman EL, Holmes DR, et al. Effects of acute changes in canine $L V$ chamber and shape on accuracy of impedance catheter estimates of $L V$-chamber volume. Biomedical Instrumentation and Technology 1994;28:113-22.

34) Grossman W, Braunwald E, Mann T, McLaurin LP, Green LH. Contractile state of the left ventricle in man as evaluated from end-systolic pressure-volume relations. Circulation 1977;56:845-52.

35) Magorien DJ, Shaffer P, Bush CA, et al. Assessment of left ventricular pressure-volume relations using gated radionuclide angiography, echocardiography and micromanometer pressure recordings. Circulation 1983;67:844-53.

36) Kronenberg MW, Parrish MD, Jenkins DW, et al. Accuracy of radionuclide ventriculography and end-systolic pressurevolume relations. J Am Coll Cardiol 1985;6:1064-72.

37) Starling MR, Walsh RA, Dell'Italia LJ, Mancini GBJ, Lasher JC, Lancaster JL. The relationship of various measures of end-systole to left ventricular maximum timevarying elastance in man. Circulation 1987;76:32-43.

38) Grossman W, Braunwald E, McLaurin LP, Green LH. Contractile state of the left ventricle in man as evaluated from end-systolic pressure-volume relations. Circulation 1977;56:845.

39) Obsbakken M, Bove AA, Spann JF. Left ventricular function in chronic aortic regurgitation with reference to end-systolic pressure, volume and stress relations. Am J Cardiol 1981;47:193

40) Borow KM, Neumann A, Wynne J. Senisitivity of endsystolic pressure-dimension and pressure-volume relations to the inotropic state in humans. Circulation 1982;62:116.

41) McKay RG, Aroesty JM, Heller GV, Royal HD, Warren SE, Grossman W. Assessment of the end systolic pressurevolume relationship in human beings with the use of a time-varying elastance model. Circulation 1986;74:97.

42) Konstam MA, Cohen SR, Salem DN, et al. Comparison of left and right ventricular end-systolic pressure-volume relations in congestive heart failure. J Am Coll Cardiol 1985;5:1326-34.

43) Aroney CN, Hermann HC, Semigran MJ, Dec W, Boucher CA, Fifer MA. Linearity of the end-systolic pressurevolume relation in patients with severe heart failure. $J$ Am Coll Cardiol 1989;14:127-34.

44) Hermann HC, Ruddy TD, Dec GW, Strauss HW, Boucher CA, Fifer MA. Inotropic effect of enoximone in patients with severe heart failure. Demonstration by left ventricular end-systolic pressure-volume analysis. J Am Coll Cardiol 1987;9:1117-23.

45) Fisher JP, Mikan JS, Rossow E, et al. Pressure dimension analysis of regional left ventricular performance using echocardiographic automated boundary detection: Validation in an animal model of inotropic modulation [abstract]. J Am Coll Cardiol 1992;19 Suppl A:262A.

46) Gorcsan J, Gasior TA, Deneault LG, Mandarino WA, Kormos RL, Hattler BG. Transesophageal echocardiographic automated border detection for intraoperative evaluation of left ventricular pressure-area relationships [abstract]. J Am Coll Cardiol 1992;19(Suppl A) :55A.

47) Gorcsan J, Romand JA, Mandarino WA, Deneaull LG, Pinsky MR. Assessment of left ventricular performance by on-line pressure area relations using echocardiographic automated border detection. J Am Coll Cariol 1994;23: 242-52.

48) Lang R, Bednarz J, Wseinert L, Balasia B, Korcarz C, Marcus R. End-systolic pressure-area relation: A noninvasively accessible index of regional myocardial contractility [Abstract]. J Am Coll Cardiol 1993;21:298A.

49) Gorcsan J, Murali S, Counihan PJ, Mandarino WA, Kormos RL. Right ventricular performance and contractile reserve in patients with severe heart failure. Circulation 1996;94:3190-7.

50) Fisher JP, McKay RG, Rosow E, et al. On line derivation of human left ventricular pressure-volume loops and load independent indices of contractility using echocardiography with automatic boundary detection: A clinical reality [Abstract]. Circulation 1993;88:305A.

51) Gorcsan J, Denault A, Mandarino WA, Pinsky MR. Left ventricular pressure-volume relations with transesophageal echocardiographic automated border detection: Comparison with conductance-catheter technique. Am Heart J 1996; 131:544-52. 